very important, I am of the opinion that no psychometric instrument should be used clinically until it has been administered to a suitable sample and the results have been subject to the usual peer-review process. If these vital steps are abandoned as unnecessary, we have no idea what the instrument is measuring or whether results amount to positive therapeutic change. Given that numerous other freely available instruments have been published and validated within a range of clinical samples (see Campbell-Orde et al and Burgess et al ${ }^{2}$ for two excellent reviews), it is puzzling that services are choosing to use an instrument where the basic statistical data are not available.

1 Cambell-Orde M, Chamberlin J, Carpenter M, Leff HS. Measuring the Promise: A Compendium of Recovery Measures, Volume II. Human Services Research Institute, 2005 (http://www.power2u.org/downloads/ pn-55.pdf)

2 Burgess P, Pirkis J, Coombs T, Rosen A. Review of Recovery Measures, Version 1.01. National Mental Health Strategy, Australian Mental Health Outcomes and Classification Network (AMHOCN), 2010 (http:// amhocn.org/static/files/assets/afdedaa1/ Review_of_Recovery_Measures.pdf).

Peter I. Beazley, Chartered Clinical Psychologist, South Essex Partnership NHS Foundation University Trust, email: peter.beazley@ corpus-christi.oxon.org

doi: $10.1192 / \mathrm{pb} .35 .5 .196 a$

\section{Prioritising the physical health needs of patients on clozapine}

During an audit conducted between 2005 and 2007, we examined glucose and cholesterol monitoring in all patients on clozapine in Glasgow $(n=569)$. Using a computerised laboratory results system, we identified whether plasma glucose or cholesterol had been monitored in the preceding 12 months. Demographic data were comparable to the findings of Bolton, with our patients having a mean age of 39 years and $73 \%$ being male. We were unable to determine whether blood samples were fasting, but we found only $46 \%(n=263)$ had undergone glucose monitoring. Of these, 68 (26\%) were $\geqslant 7.8 \mathrm{mmol} / \mathrm{I}$ and $25(10 \%)$ were $>11 \mathrm{~mol} / \mathrm{I}$. In relation to cholesterol monitoring, only 192 individuals (34\%) had been tested, of whom $123(64 \%)$ had cholesterol $\geqslant 5 \mathrm{mmol} / \mathrm{l}$. Our findings and those of Bolton indicate that a significant number of patients on clozapine continue to be unmonitored in relation to important metabolic markers, and of those who are tested, a substantial proportion have abnormal results. These factors may be contributing to the increasing mortality gap faced by this group of patients with complexity. As Taylor et al ${ }^{2}$ demonstrated, standardised mortality rates are significantly increased in patients on clozapine, with a fourfold risk of dying compared with individuals receiving long-acting risperidone injection. Bolton advocates for specialist secondary care physical health clinics to ensure appropriate follow-up and to optimise communication with primary care. We are concerned that within the current economic climate, additional resources will not be made available for service development to address these needs. There is a remaining onus on mental health services to engage proactively and creatively within existing primary and secondary care services and in targeting early non-pharmacological intervention, for which there is an increasing evidence base. ${ }^{3}$
1 Bolton PJ. Improving physical health monitoring in secondary care for patients on clozapine. Psychiatrist 2011; 35: 49-55.

2 Taylor DM, Douglas-Hall P, Olofinjana B, Whiskey E, Thomas A Reasons for discontinuing clozapine: matched, case-control comparison with risperidone long-acting injection. Br J Psychiatry 2009; 194: 165-7.

3 Álvarez-Jiménez $M$, Hetrick SE, González-Blanch $C$, Gleeson JF, McGorry PD. Non-pharmacological management of antipsychoticinduced weight gain: systematic review and meta-analysis of randomised controlled trials. Br J Psychiatry 2008; 193: 101-7.

Sarah L. Ward, locum consultant psychiatrist in old age psychiatry, Stobhill Hospital, Glasgow, Scotland, UK, email: Sarah.Ward@ggc.scot.nhs.uk, Selena Gleadow Ware, ST5 in general adult psychiatry, Inverclyde Royal Hospital, NHS Greater Glasgow and Clyde, Ciara Kelly, consultant in rehabilitation psychiatry, Leverndale Hospital, NHS Greater Glasgow and Clyde.

doi: $10.1192 / p b .35 .5 .197$

\section{Supervised community treatment}

Sarah Woolley suggested that given the lack of robust scientific evidence of the benefits of supervised community treatment (SCT), it was questionable whether psychiatrists in England and Wales would take advantage of the new SCT powers introduced in $2008{ }^{1}$

Although the collection of SCT data is still in its infancy, we have in recent months seen two reports on SCT usage. The Mental Health Alliance's briefing on $\mathrm{SCT}^{2}$ highlighted that the use of SCT in its first year was significantly higher than the government expected. From a survey of all active and retired members of the Royal College of Psychiatrists that received 533 responses, 324 members thought the SCT powers useful, whereas 74 did not.

The Care Quality Commission's first annual report on the Mental Health $\mathrm{Act}^{3}$ confirmed the high use of SCT. In a sample of 208 cases, the Commission found that $30 \%$ of patients subject to SCT did not have a reported history of nonadherence or disengagement - 'This suggests that the high use of CTOs ... could be a result of the powers being applied preventatively beyond the group of patients for whom they were primarily designed'.

We await better data on SCT from the Oxford Community Treatment Order Evaluation Trial (OCTET). In the meantime, however, it does appear that psychiatrists (and, of course, those approved mental health professionals who agree with them) are not being shy in using the SCT powers. In passing, it is worth noting that having an estimated 4000-5000 people living in the community under an SCT has led to no corresponding reduction in numbers of detained in-patients.

1 Woolley S. Involuntary treatment in the community: role of community treatment orders. Psychiatrist 2010; 34: 441-6.

2 Lawton-Smith S. Briefing Paper 2: Supervised Community Treatment. Mental Health Alliance, 2010 (http://www.mentalhealthalliance.org.uk/ resources/SCT_briefing_paper.pdf).

3 Care Quality Commission. Monitoring the Use of the Mental Health Act in 2009/10. Care Quality Commission, 2011 (http://www.cqc.org.uk/ mentalhealthactannualreport2009-10.cfm).

\section{Declaration of interest}

The Mental Health Foundation is a member of the Mental Health Alliance.

Simon H. Lawton-Smith, head of policy, Mental Health Foundation, London, email: slawton-smith@mhf.org.uk

doi: 10.1192/pb.35.5.197a 